\title{
Familiarity and relational preference in the understanding of noun-noun compounds
}

\author{
GEORGIOS TAGALAKIS and MARK T. KEANE \\ University College Dublin, Dublin, Ireland
}

\begin{abstract}
When people are presented with noun-noun compounds, they tend to produce two main types of interpretation: relational and property interpretations. One theory of compounding maintains that relational interpretations are preferred over property ones. However, many of the studies supporting this relational preference hypothesis appear to be vitiated by a failure to control for the familiarity of compounds. A rating study on so-called "novel" compounds used in previous studies is reported, which shows that many can be considered to be familiar. Then two experiments in which familiarity is controlled are presented, to test the relational preference hypothesis, using a sensibility judgment task (Experiment 1) and a comprehension judgment task (Experiment 2). The results show that familiarity has a clear effect on the ease of understanding of noun-noun compounds but that there is no hard evidence for relational preference. The implications of these results for the empirical literature and for current theories are discussed.
\end{abstract}

Combinations of concepts are regularly used in everyday life to coin new names for new objects and to extend the boundaries of our language (Jespersen, 1942). Indeed, most of the new phrases entering the language each year are made from combinations of existing words (e.g., laptop computer, video player, and soccer mom). As new compounds enter a language, they are understood by the language community, exhibiting some of the fundamental generativity of natural language (see, e.g., Costello \& Keane, 1997, 2000, 2001; Gagné, 2000; Lynott, Tagalakis, \& Keane, 2004; Tagalakis \& Keane, 2004; Wisniewski, 1996). Typically, it has been found that even apparently simple novel compounds admit great combinatorial richness in their semantics; for example, the compound finger cup could be "a cup to clean fingers in," "a thin cup that is the width of a finger," "a cup shaped like a finger," and so on. The attempt to explain these and other phenomena are the main drivers of empirical and theoretical research into conceptual combination.

In this article, two key aspects of conceptual combination that provide us with important empirical leverage in distinguishing between different models of combination are examined: relational preference and familiarity. As will be shown, the resolution of these two issues has significant implications for our theoretical understand-

This work was funded by a grant from University College Dublin to the second author. We thank Fintan Costello, the members of the UCDTCD Cognitive Science Group, and three anonymous reviewers for their useful comments on the work. Correspondence concerning this article should be addressed to G. Tagalakis, School of Computer Science and Informatics, University College Dublin, Belfield, Dublin 4, Ireland (e-mail: georgios.tagalakis@ucd.ie).

Note-This article was accepted by the previous editorial team, when Colin M. MacLeod was Editor. ing of conceptual combination and the adequacy of past empirical work.

\section{Relational Preference}

In recent years, there has been considerable controversy about whether people have a preference for some interpretations of novel compounds over others (see Costello \& Keane, 1997; Gagné, 2000; Wisniewski, 1996; Wisniewski \& Gentner, 1991; Wisniewski \& Love, 1998). Two main types of interpretation have been identified in the diversity of meanings that people produce for novel compounds: relational and property interpretations. Relational interpretations hinge on a relation being found to connect the two concepts (e.g., "a cup to clean fingers in," where to-clean-in is the relation that connects finger and cup; see Murphy, 1988, 2002). Property interpretations hinge on asserting a property that belongs to one concept of the other concept (e.g., "a thin cup," where the property thin is used from finger; see Wisniewski \& Gentner, 1991). Recently, it has been argued that relational interpretations are the preferred interpretations and that property interpretations are considered only when no relational ones can be found (Gagné \& Shoben, 1997; Shoben \& Gagné, 1997). As Shoben and Gagné claimed, "We do not dispute that property matches occur; however, we contend that property matches are the interpretation of last resort" (p. 35). We call this view the relational preference hypothesis.

\section{Evidence for Relational Preference}

The relational preference hypothesis is supported by a variety of studies in which different measures have been used. Several corpus studies have shown that the majority of compounds used in the language are relational ones (Downing, 1977; Gagné, 2000). But perhaps the most convincing evidence for the relational preference hypothesis has come from a series of experiments by Gagné (2000). 
Gagné (2000) tested the relational preference hypothesis by using an on-line paradigm in which participants were asked to rate the sensibility of relational and property compounds (i.e., compounds known to be interpreted in a relational or property way). The key findings were that relational compounds were more likely to be judged sensible and were judged to be sensible more quickly than property compounds (see Gagné, 2000, Experiments 1 and 2). These results have been supported by other experiments showing that relational interpretations were preferred regardless of priming manipulations; they were rated more acceptable than property ones and appeared to be more easily understood (see Gagné, 2000, Experiments 3 and 4). Taken together, these findings appeared to show a strong preference for relational interpretations over property ones.

However, this support for the relational preference hypothesis has been countered by evidence showing that property interpretations can also commonly occur. Costello and Keane (1997) reported studies in which 33\% of the interpretations produced were property ones. Markman and Wisniewski (1997) have shown that property interpretations increase in number when the constituent concepts in the compound are similar, rather than dissimilar (e.g., elephant pig, as opposed to elephant car). More directly, Wisniewski and Love (1998) tested the relational preference hypothesis, showing that combinations with plausible relations were more often interpreted with properties when their constituents were highly similar. They also showed that property interpretations characterize the meanings of a number of familiar combinations in the English language (e.g., fox grape and guitar fish). Others have argued that property interpretations are more likely to occur under different conditions - for instance, that they arise from the metaphoricity of compounds (Glucksberg, McGlone, \& Manfredi, 1997; Goldvarg \& Glucksberg, 1998) or when constituents are natural kinds (Bock \& Clifton, 2000). Whatever the root causes, what is clear from these studies is that property interpretations can occur quite frequently.

Taken together, these findings suggest that relational preference cannot be assumed. However, none of the studies supporting property interpretations has addressed ease of understanding, as Gagné's (2000) on-line measures did. Rather, they provide more circumstantial evidence from frequency-of-production measures.

\section{The Theoretical Importance of Relational Preference}

Relational preference is important because it can be used to decide between the different models of conceptual combination. Gagné's (2000; Gagné \& Shoben, 1997) CARIN model accounts for the production of relational interpretations as a process of selecting a relation from a set of relations previously associated with the compound's words. For example, mountain bird is interpreted as "a bird that lives in mountains" because most existing compounds in the language of the mountain something form tend to use the located-in relation (e.g., mountain lodge, mountain lake, and mountain path). As such, this model concentrates solely on the combination processes that generate relational interpretations; property interpretations are seen as a small, residual class handled by less well specified mechanisms (see Gagné, 2002).

In contrast, Wisniewski's (1996) dual-process model explicitly posits two processes for handling the two classes of interpretations. Relational interpretations are produced by a concept specialization process, whereas property interpretations are produced by an analogical alignment process (cf. Cohen \& Murphy, 1984; Gentner, 1983; Keane, Ledgeway, \& Duff, 1994; Murphy, 1988). Costello and Keane's (2000) constraint model goes a step further in proposing a unitary combination mechanism that produces both relational and property interpretations, depending on what emerges as the best interpretation from one's prior knowledge. It is clear that both of these models show no preference for producing relational interpretations in their respective mechanisms. Hence, if the relational preference hypothesis is right, they are wrong.

As was noted earlier, the strongest evidence for the relational preference hypothesis comes from Gagné's (2000) findings from on-line sensibility judgments and other measures. This evidence is revisited, in the light of the issue of familiarity, to determine which model best characterizes conceptual combination.

\section{Familiarity}

All studies of conceptual combination purport to use novel compounds, because only novel compounds allow us to determine how previously unrelated concepts can be combined to generate new meanings (Hampton, 1987). However, few studies explicitly justify the novelty of the compounds used but, rather, rely on untested experimenter intuitions. For studies in which the general nature of the interpretations produced is examined, this practice is probably acceptable. For on-line studies assessing more fine-grained differences between interpretation types, such as those involving relational preference, it is definitely not an acceptable practice. If a set of supposedly novel compounds actually contains nonnovel compounds, response times to those materials will be vitiated.

Unfortunately, this very problem may have occurred in the previous tests of relational preference. Some of the Gagné's (2000) compounds appear to be quite familiar; for instance, her material set includes gas cloud and office plant (see Appendix A). More worryingly, the distribution of these familiar compounds does not appear to be balanced across the different material sets; all the familiar compounds appear to occur in the relational compound set, and none in the property compound set. As such, the relational preference effects found could be due just to the unbalanced occurrence of familiar compounds in the material sets.

This criticism assumes that familiarity matters, an issue about which more could be known. Intuitively, one would expect a familiar compound to be understood more easily 
and rapidly than a novel compound. A familiar compound is likely to be stored as a single lexical entry whose meaning can be accessed swiftly, whereas a novel compound will require separate lexical access to the compound's constituents, followed by the construction of some novel meaning. Such familiarity effects on understanding have been repeatedly shown for single words (e.g., Blasko \& Connine, 1993; Connine, Mullennix, Shernoff, \& Yelen, 1990; Gernsbacher, 1984).

Although there is some work on the familiarity of compounds (e.g., Gray \& Smith, 1995; Springer \& Murphy, 1992), we know of no studies that have shown that familiar compounds are more easily understood. For example, Gray and Smith have shown that people can easily retrieve more instances from familiar complex concepts than from unfamiliar ones. They also argued that some previous studies might have used familiar items (e.g., Medin \& Shoben, 1988; Murphy, 1988). However, these results tell us more about instance retrieval than about conceptual combination per se. They do not show directly that the processing of a familiar compound takes less time than the processing of an unfamiliar one does.

In this article, two experiments that explicitly test whether familiarity facilitates the ease of understanding of noun-noun compounds are reported, and the implications of such a finding for the relational preference hypothesis are considered. It is worth pointing out that this interest in familiarity does not stop at merely controlling its impact in conceptual combination research. The comprehension of familiar compounds may tell us something about the understanding of novel compounds. Even in truly novel compounds, there may be subtle influences from related, familiar compounds. For example, the compound bullet car could be shown to be novel, yet one's understanding of it may rely on the more familiar compound bullet train. In this vein, Shoben (1993) has previously pointed out that some novel compounds appear to be understood by analogy to known compounds; Irangate does not make much sense without recourse to Watergate, since the $X$ gate construction has come to mean "political scandal that goes right to the top on an issue associated with $\mathrm{X}$ " (see also Gagné, 2001; Hoey, 2005; Keane \& Costello, 2001; Keane et al., 1994). Thus, it may well be the case that to truly understand novel compounds, it is necessary first to understand familiar compounds better.

\section{Outline of Key Questions and Experiments}

In the remainder of this article, several studies that have tackled the issue of familiarity and relational preference will be presented. There are three key questions that we will attempt to answer.

1. Has familiarity been adequately controlled in previous studies? To answer this question, a rating study employing compounds previously used in the literature was performed. In general, sufficient evidence is found to question the validity of previous findings on relational preference (see the Rating Study section).

2. Do the key results for relational preference still hold when suitably controlled stimuli are used? To answer this question, we reran Gagné's (2000) sensibility judgment task, in which the variables of familiarity (familiar vs. unfamiliar) and compound type (relational vs. property) are crossed. The results do not provide clear support for relational preference (see Experiment 1).

3. Is there other, converging evidence for relational preference in people's comprehension of compounds? With a suitably controlled set of stimuli, an on-line comprehension task was used in which the variables of familiarity (familiar vs. unfamiliar) and compound type (relational vs. property) were crossed. This quest for converging evidence from different measures also does not strongly support relational preference and conveys a picture of compound comprehension that is more complex than previously appreciated (see Experiment 2).

\section{RATING STUDY The Familiarity of Compounds}

To carry out the two experiments outlined above, it was first necessary to determine which compounds were familiar and which were unfamiliar. This problem was tackled by gathering people's familiarity ratings for a large number of compounds that had been used previously in the literature (even though all of the studies from which these compounds were drawn had assumed them to be novel and unfamiliar). These consensual ratings were substantiated by frequency counts based on corpus searches.

\section{Method}

Materials. Two hundred fourteen compounds, largely drawn from previous studies, were used (Estes \& Glucksberg, 2000; Gagné, 2000; Gagné \& Shoben, 1997; Wisniewski, 1996). Half of them $(n=$ 107) had been previously classified as relational compounds; that is, they had been shown to invite relational interpretations. The relational compounds came from Gagné (2000, Experiments 1 and 2) and Gagné and Shoben (1997, Experiment 3), with duplicate items removed. These relational compounds were also subclassified, following Gagné and Shoben, on the basis of the relative frequency of the relation used in the interpretation for both the modifier and the head terms. Thirty-nine compounds had a highly frequent relation for both the modifier and the head (termed the $H H$ category), 27 compounds had a relation that was highly frequent for the modifier but low in frequency for the head (termed the $H L$ category), and 41 involved a relation that was highly frequent for the head but low in frequency for the modifier (the $L H$ category). The other half of the items $(n=107)$ had previously been classified as property compounds. Thirty-two of these property compounds came from Gagné (2000, Experiments 1 and 2) and, in turn, had been drawn from Wisniewski (1996); half of these compounds used similar nouns, and half used dissimilar nouns. A further 13 compounds, all with dissimilar nouns, were drawn from Estes and Glucksberg (2000). The remaining 62 property compounds, all with dissimilar nouns, were drawn from a variety of sources.

Procedure. The materials were presented in booklet form with one compound to each page, and people were asked to rate each for its familiarity or unfamiliarity. As such, including the instruction sheet, each booklet was 215 pages long. The instruction sheet described the task for the participants, using one familiar and one unfamiliar example, with an indicative rating for each.

The participants were asked to rate the compound on a continuous scale running from 1 (very unfamiliar) to 7 (very familiar). It was explicitly stated that the participants should not base their judg- 
ments on the sensibility of the phrase but, rather, on whether they had encountered the phrase before and how frequently. The order of phrases in each booklet was randomly ordered. The participants proceeded through the booklets at their own pace, taking, on average, about $30 \mathrm{~min}$ to complete the task.

Participants. Thirty-nine English-speaking University College Dublin employees and students volunteered to take part in the experiment. The group consisted of 18 women and 21 men between the ages of 21 and 45 years.

Scoring. A compound was classified as familiar, for purposes of analysis, if the majority of people $(>50 \%)$ deemed it to be familiar and unfamiliar if the majority of people $(>50 \%)$ rated it as unfamiliar; otherwise, it was considered as neutral.

\section{Results and Discussion}

According to the previous studies from which these compounds were drawn, all of these compounds are novel. It was, therefore, quite surprising to find that in the set of 214 compounds, 61 were judged to be familiar, with the remaining compounds considered to be unfamiliar $(n=$ $145)$ or neutral $(n=8)$.

Of the 107 relational compounds rated, about a third were familiar $\left[n_{\mathrm{F}}=35(32.7 \%) ; M_{\mathrm{F}}=4.83, S D_{\mathrm{F}}=0.74\right]$, with the remaining two thirds being unfamiliar $\left[n_{\mathrm{UF}}=65\right.$ $\left.(60.7 \%) ; M_{\mathrm{UF}}=2.47, S D_{\mathrm{UF}}=0.60\right]$ or neutral $\left[n_{\mathrm{N}}=7\right.$ $\left.(6.5 \%) ; M_{\mathrm{N}}=3.62, S D_{\mathrm{N}}=0.27\right]$. Of the 107 property compounds rated, about a quarter were familiar $\left[n_{\mathrm{F}}=\right.$ $\left.26(24.3 \%) ; M_{\mathrm{F}}=5.28, S D_{\mathrm{F}}=0.87\right]$, with the remaining three quarters being unfamiliar $\left[n_{\mathrm{UF}}=80(74.8 \%)\right.$; $\left.M_{\mathrm{UF}}=1.85, S D_{\mathrm{UF}}=0.57\right]$ and neutral $\left[n_{\mathrm{N}}=1(0.9 \%)\right.$; $\left.M_{\mathrm{N}}=4.03, S D_{\mathrm{N}}=0\right]$. Appendix B contains a full list of the compounds classified as familiar. Appendix $\mathrm{C}$ lists all the property-based compounds, along with the percentages of people who judged them to be familiar or unfamiliar and the mean familiarity ratings.

Familiarity ratings and frequency counts in corpora. When familiarity has been considered as a variable, there has been some controversy as to whether it is best captured by consensual ratings (as has been done above) or by more "objective" frequency counts from corpora. There are arguments for and against either approach. The main problem with consensual ratings of familiarity is that they may well reflect other variables (e.g., sensibility or comprehensibility); for instance, people may never have previously encountered oil stove, but because it can be easily comprehended, they may think that it is more familiar. The main problem with the frequency count approach to familiarity is that it depends on the coverage of the corpus (Kilgarriff \& Grefenstette, 2003); according to the British National Corpus (BNC; Burnard, 1995), zebra fish is quite frequent, with 24 hits coming from two technical articles, whereas fork tongue does not attract any hits. Since no one measure seemed perfect, a middle course of determining whether there was good agreement between our consensual ratings and frequency count measures was adopted.

The evidence suggests that our raters' assessments of familiarity were quite consistent with what is found in a frequency count assessment of familiarity, although the match between both measures is not perfect. The authors queried the BNC for all the noun-noun pairs used in the rating study. The frequency of each noun-noun pair found in the BNC, when it was used as a noun compound, was counted after inspection of the sentence context(s) in which it appeared. It was found that compounds classified as being familiar had reliably higher frequency $(M=$ $152.25)$ than did those classified as being unfamiliar $(M=$ 82.99) (Mann-Whitney $U=1,449, Z=-8.98, p<.001$, two-tailed). Also, the $\phi$ coefficient of correlation between people's classification of the compounds (familiar or unfamiliar) and the $\mathrm{BNC}$ hits (occurrence or not occurrence in the corpus $)$ is high and positive $(N=206, \phi=.59, p<$ .001 ). Forty-eight of the 61 compounds rated as familiar are found in the BNC, and the remaining 13 are not; ${ }^{1}$ however, all but one of these 13 compounds receive more than 200 "clean" hits in a Google search, ${ }^{2}$ suggesting that they are not as infrequent as the BNC would suggest. One hundred twenty of the 145 compounds rated to be unfamiliar receive no hits in the BNC, whereas the remaining 25 compounds have very low hits $(M=2.61, S D=$ 0.65 ). To look at the data another way, leaving aside the 8 compounds rated as neutral, there was $82 \%$ agreement between people's classification of the compounds as familiar or unfamiliar and the BNC classification as occurring or not occurring. Thus, we can be reasonably satisfied that our adopted measure of rated familiarity is supported by frequency count measures.

Implications for previous findings. One of the three questions posed earlier was, Has familiarity been adequately controlled in previous studies? This question has important implications for the key findings on relational preference. The evidence of our rating study, augmented with corpora searches, suggests that familiarity has not been adequately controlled, since a nonnegligible number of compounds considered to be novel in previous studies are, in fact, familiar.

A detailed analysis of specific studies is even more revealing. It was noted earlier that Gagné's (2000) key evidence for relational preference appeared to use material sets with unbalanced numbers of familiar compounds. All of these compounds $(N=64 ; 32$ property and 32 relational) were assumed to be unfamiliar. Yet the ratings above show that although almost all the property compounds used in Gagné's (2000) study were judged to be unfamiliar $\left(n_{\mathrm{UF}}=31 ; M_{\mathrm{UF}}=2.40, S D_{\mathrm{UF}}=0.53\right)$, about one third of the relational compounds were judged to be familiar $\left(n_{\mathrm{F}}=12 ; M_{\mathrm{F}}=4.71, S D_{\mathrm{UF}}=0.74\right)$, with the others being unfamiliar $\left(n_{\mathrm{UF}}=20 ; M_{\mathrm{UF}}=2.40, S D_{\mathrm{UF}}=\right.$ $0.53)$. As such, all of the evidence given in this study for relational preference must be called into question. If the relational compounds were more familiar, one would expect them to be processed more quickly and easily than a set of unfamiliar property compounds. Note that it is assumed here that familiar compounds are easier to process. This proposal remains to be empirically proven.

\section{EXPERIMENT 1 Sensibility, Preference, and Familiarity}

The previous rating study has shown that many of the compounds previously assumed to be novel are actually 
familiar. This result suggests that previous findings on people's preference for relational compounds over property ones are unsafe. Since familiarity has not been adequately controlled in these studies, the effects found may be due purely to familiarity. However, this argument rests on the assumption that familiar compounds are, indeed, easier to understand than unfamiliar compounds. In this experiment, the familiarity hypothesis was tested, and an attempt also was made to answer the second question, Is there converging evidence for preference in people's comprehension of compounds?

In this experiment, we reran Gagné's (2000) sensibility judgment task with the relational and property compounds suitably controlled for familiarity. In general, we would expect the familiar compounds to be judged to be sensible more quickly than are the unfamiliar ones. If Gagné's (2000) findings are not vitiated by the poor control of familiarity, one should find a preference for relational compounds, manifested by their being judged to be sensible more quickly than are the property compounds. Indeed, there may well be an interaction between compound type and familiarity, with the unfamiliar relational compounds being judged more quickly than the unfamiliar property ones.

\section{Method}

Materials. Eighty-four compounds from those used in the rating study were selected to create four material sets: 16 familiar relational compounds, 26 unfamiliar relational compounds, 17 familiar property compounds, and 25 unfamiliar property compounds. The materials sets met several constraints.

1. The mean familiarity ratings for the relational compounds $(M=3.42, S D=1.47)$ and the property compounds $(M=3.15$, $S D=1.74)$ were not reliably different $[F(1,82)=0.64, p>.1]$.

2. The mean word length for the relational items $(M=11.36$, $S D=2.66)$ and the property items $(M=10.50, S D=2.38)$ was not reliably different $[F(1,82)=2.42, p>.1]$.

3 . The relational items were subdivided into roughly equal numbers of HH, HL, and LH compounds on the basis of Gagnés previous classifications $\left(n_{\mathrm{HH}}=13, n_{\mathrm{HL}}=15\right.$, and $\left.n_{\mathrm{LH}}=12\right)$. These groups had little familiarity variance between them $[F(2,39)=$ $0.15, p>.5]$, were roughly equally distributed in the familiarity condition $\left(n_{\mathrm{HHF}}=5, n_{\mathrm{HLF}}=6, n_{\mathrm{LHF}}=6, n_{\mathrm{HHUF}}=8, n_{\mathrm{HLUF}}=9\right.$, and $n_{\mathrm{LHUF}}=9$ ), and finally, had little word length variance between them $[F(2,39)=0.51, p>.5]$.

4. The number of duplicate words in the whole set of compounds was minimized ( 6 words in the relational category and 1 word in the property category, out of 168 words used in total).

All of the compounds were rated as having a sensible interpretation by the authors and three independent raters, with $91 \%-100 \%$ agreement. A further 42 filler compounds, constructed by randomly combining nouns with no sensible interpretation, were added to this set for the experiment ${ }^{3}$ (see Appendix D for a full list of materials).

Procedure. The procedure was identical to that used by Gagné (2000, Experiment 1). The participants were instructed to judge the sensibility of compounds presented in a computerized, on-line task. The on-screen instructions asked them to read a compound on each of the subsequent screens and indicate whether it was sensible or nonsensible to them as accurately and quickly as possible. Before each compound was presented, the word "Ready?" appeared on the PC screen. After the participants pressed the space bar with their thumbs, the compound appeared in the center of the screen, to which the participants had to respond by pressing either the "sense" or the "nonsense" key. For half the participants, the " $J$ " key was the "sense" key, and the "F" key was the "nonsense" key. For the other half of the participants, the mapping to the keys was reversed. The response time measure was based on the time taken to press either key after the presentation of the compound on screen.

The experiment was preceded by a practice session that involved 10 trials in which five sensible and five nonsensible compounds were presented. The materials were randomly ordered for each participant. The participants were tested individually, with each experimental session taking about $30 \mathrm{~min}$ to complete.

Participants. Thirty-four native English-speaking undergraduates from University College Dublin volunteered to take part in the experiment. The group consisted of 10 women and 24 men between the ages of 19 and 24 years.

Measures and scoring. Following Gagné (2000), the main measure used was the response time taken to judge a presented compound as being sensible (i.e., if a compound was judged nonsensible, it was excluded from the analysis). As was the case in Gagné's (2000) study, although we had established that all the target compounds had a sensible interpretation, a proportion of these compounds were judged by people to be nonsensible (see Table 1). To provide a clear picture of the data, our second measure was the proportion of sensibility judgments made to the compounds. The data of 5 participants with error rates equal to or exceeding $30 \%$ were excluded prior to analysis. Across the remaining participants, the response times on 32 trials greater than $3 S D$ s from each participant's grand mean were omitted.

\section{Results and Discussion}

The results confirmed the intuition that familiar compounds are more easily understood than unfamiliar compounds. Interestingly, having appropriately controlled familiarity, little evidence was found to support the relational preference view. However, there were some hints that relational compounds are treated differently from property compounds under some measures.

Response times to sensibility judgments. The response times (in milliseconds) taken by the participants for those compounds judged to be sensible were submitted to two-factor, repeated measures ANOVAs. The two withinsubjects factors were compound type (relational or property) and familiarity (familiar or unfamiliar), and the analysis was carried out by participants $\left(F_{1}\right)$ and by items $\left(F_{2}\right)$. For the by-participants analysis, compound type and familiarity were treated as fixed factors, whereas participants was the random factor. For the by-items analysis, items nested within the compound type and familiarity conditions were the random factor. Calculations were done using general linear model procedure for unbalanced designs with all possible factors and interactions defined in the model.

The analyses revealed a main effect of familiarity, with the familiar compounds $(M=1,379.95, S D=826.79)$

Table 1

Proportions (Counts and Row Percentages) of Experimenters' Familiar and Unfamiliar Relational and Property Compounds Judged as Sensible or Nonsensible in Experiment 1

\begin{tabular}{lccccr}
\hline \multirow{2}{*}{\multicolumn{1}{c}{ Condition }} & \multicolumn{2}{c}{ Sensible } & & \multicolumn{2}{c}{ Nonsensible } \\
\cline { 2 - 3 } \cline { 6 - 6 } & Count & $\%$ & & Count & $\%$ \\
\hline Relational familiar & 427 & 92.0 & & 37 & 8.0 \\
Relational unfamiliar & 475 & 63.0 & & 279 & 37.0 \\
Property familiar & 440 & 89.2 & & 53 & 10.8 \\
Property unfamiliar & 347 & 47.9 & & 378 & 52.1 \\
\hline
\end{tabular}


being judged sensible more quickly than the unfamiliar compounds $(M=1,799.47, S D=1,015.86)\left[F_{1}(1,30)=\right.$ $49.75, M S_{\mathrm{e}}=1,358,551, p<.001 ; F_{2}(1,90)=68.74$, $\left.M S_{\mathrm{e}}=1,194,127, p<.001\right]$. Although the property compounds $(M=1,529.61, S D=957.87)$ were judged more quickly than the relational compounds $(M=1,630.20$, $S D=934.46)$, this difference was not reliable $\left[F_{1}(1,30)=\right.$ $0.02, M S_{\mathrm{e}}=783,416, p=.90 ; F_{2}(1,90)=0.24, M S_{\mathrm{e}}=$ $1,194,127, p=.63]$. There was, however, a reliable interaction between familiarity and compound type $\left[F_{1}(1,30)=\right.$ $14.46, M S_{\mathrm{e}}=627,745, p=.001 ; F_{2}(1,90)=7.17, M S_{\mathrm{e}}=$ $1,194,127, p=.01]$. The means and standard deviations for the four conditions were as follows: relational familiar, $M=1,474.05, S D=848.19$; relational unfamiliar, $M=$ $1,771.11, S D=985.85$; property familiar, $M=1,288.86$, $S D=795.96$; property unfamiliar, $M=1,838.64, S D=$ $1,056.14$.

To understand the interaction further, the random factors were removed from the model to examine pairwise contrasts, given that pairwise contrasts between the means with random factors are not meaningful. This reanalysis did not change the significance levels of the effects found, so the pairwise differences found can be read as indicative tendencies. A Tukey's HSD test showed no reliable difference between the relational unfamiliar compounds and the property unfamiliar compounds in both the byparticipants and the by-items pairwise analyses $(p=.08$ and .30 , respectively).

The main message from this response time measure is that familiar compounds are more easily understood, confirming our intuitions. Furthermore, in contrast to previous studies, it has been found that when appropriate control of familiarity is used, there is no evidence to suggest that relational compounds are preferred to property ones. ${ }^{4}$

In light of our earlier discussions about whether frequency counts from corpora or familiarity ratings from people best capture familiarity, there are grounds for analyzing these data using the other measure. We, therefore, characterized familiarity using the $\mathrm{BNC}$ data (occurrence or not occurrence) and submitted the response time data to new two-way ANOVAs, by participants and by items, with the same model specifications. As was expected, the response times were reliably shorter for phrases occurring in the corpus $(M=1,451.52, S D=891.82)$ than for those not occurring in the corpus $(M=1,736.66, S D=985.06)$ $\left[F_{1}(1,30)=41.16, M S_{\mathrm{e}}=929,443, p<.001 ; F_{2}(1,96)=\right.$ $\left.24.65, M S_{\mathrm{e}}=1,533,578, p<.001\right]$. As was found before, there was no reliable difference between the property and the relational compounds. A reliable interaction between the two factors was found, but only in the by-participants test $\left[F_{1}(1,30)=7.37, M S_{\mathrm{e}}=1,019,201, p=.01 ; F_{2}(1,96)=\right.$ $\left.1.94, M S_{\mathrm{e}}=1,533,578, p=.17\right]$. Importantly, this interaction was not due to differences between any of the key conditions; that is, the relational-occurring condition was not reliably different from the property-occurring condition $(p>.05)$, and neither was the relational-nonoccurring condition reliably different from the property-nonoccurring one $(p>.05)$. The means and standard deviations for the four conditions were as follows: relational occurring in the BNC, $M=1,523.06, S D=904.8$; relational not occurring in the $\mathrm{BNC}, M=1,737.82, S D=952.20$; property occurring in the $\mathrm{BNC}, M=1,380.61, S D=873.92$; property not occurring in the BNC, $M=1,735.07, S D=1,029.75$.

All of these analyses point in the same direction. Whichever measure of familiarity is used (frequency counts or consensual ratings), the conclusion remains the same: Familiar compounds are processed more easily than unfamiliar ones, and there is little evidence of a relational preference effect.

Frequencies of sense and nonsense judgments. In this experiment, people made quick decisions as to whether the presented compounds were sensible or nonsensible. Although all the compounds were independently rated to be sensible, different participants rated a proportion of them to be nonsensible. Clearly, in this task, when an interpretation does not come to mind quickly, some people may judge the compound to be nonsensible. Gagné (2000) used this measure as another indicator of the preference shown for relational compounds and found that proportionally more relational compounds were judged sensible than property ones.

Using this measure, two-way repeated measures ANOVAs for the factors of compound type (relational or property) and familiarity (familiar or unfamiliar) were performed. In the by-participants analysis, the dependent variable was the proportion of combinations that a participant judged to be sensible in each condition. In the by-items analysis, the dependent variable was the proportion of occasions that each combination was judged to be sensible. These analyses revealed a main effect of familiarity, with the familiar compounds $(M=89.01, S D=$ 14.55) being judged sensible more often than the unfamiliar compounds $(M=55.43, S D=17.95)\left[F_{1}(1,28)=\right.$ $119.78, M S_{\mathrm{e}}=273, p<.001 ; F_{2}(1,82)=81.89, M S_{\mathrm{e}}=$ $303, p<.001]$. There was also a main effect of compound type, with the relational compounds $(M=77.51, S D=$ 17.56) being judged sensible more often than the property compounds $(M=66.93, S D=27.25)\left[F_{1}(1,28)=20.05\right.$, $M S_{\mathrm{e}}=162, p<.001 ; F_{2}(1,82)=5.30, M S_{\mathrm{e}}=303, p=$ $.02]$. There was no reliable interaction between compound type and familiarity $\left[F_{1}(1,28)=3.40, M S_{\mathrm{e}}=177, p=\right.$ $\left..08 ; F_{2}(1,82)=2.52, M S_{\mathrm{e}}=303, p=.12\right]$. The means and standard deviations for the four conditions were as follows: relational familiar, $M=92.03, S D=7.45$; relational unfamiliar, $M=63.00, S D=11.65$; property familiar, $M=86.00, S D=18.89$; property unfamiliar, $M=$ 47.86, $S D=20.04$.

The message from this proportion measure is that familiar compounds are more easily understood than unfamiliar ones, a finding that is consistent with the response time data. However, the frequency results also show that there is a distinct tendency to judge relational compounds as sensible more often than property compounds, especially when both are unfamiliar (63\% vs. $48 \%)$. Can this be taken as a clue to a greater preference for relational compounds? 


\section{INTERIM CONCLUSIONS}

Looking across the results of the two measures used in this experiment, there is an inescapable conclusion on the issue of familiarity but a mixed message on the relational preference issue. On familiarity, irrespective of how ease of understanding is measured, one finds clear evidence that familiar compounds are more easily understood than are unfamiliar ones. On the relational preference issue, the picture is less clear. If sensibility response times are used, no evidence can be found that relational compounds are more natural than property ones, since they were not judged to be sensible reliably more quickly. However, if proportions of sensibility judgments are used, it is found that relational compounds, particularly unfamiliar ones, were considered to be sensible more often than their property compound counterparts. Why?

One possibility is that sensibility judgments are speeded responses that are sensitive to the distribution of different compounds in a language. Several researchers have pointed out that relational compounds occur more frequently in the language than do property compounds (e.g., Downing, 1977; Levi, 1978). Hence, under the conditions of a speed judgment, people may be more likely to judge them sensible, even if no detailed interpretation comes to mind. It may be that people think a relational compound sensible if there appears to be any unspecified relation connecting the two concepts (e.g., an unspecified relation, such as functionally related ). In contrast, people are less likely to think property compounds sensible, because a specific property or an appropriate set of properties must be found to regard them as sensible. Hence, there is a greater tendency to consider the property compounds to be nonsensible under this measure. This account is supported by the finding that in the unfamiliar condition, the relational compounds were more often judged to be sensible and, when sensible, were judged slightly (but not reliably) more quickly than were the property ones.

If this proposal is true, then, if we make the judgment task one that is less rushed and one that requires more consideration of the meaning of the compound, we should find that this compound type effect disappears. This is exactly what was examined in the next experiment by asking people to think of an interpretation for the compound (with a view to writing it down), rather than making a snap sensibility judgment.

\section{EXPERIMENT 2 \\ Comprehensibility, Preference, and Familiarity}

Experiment 1 confirmed the intuition, generally assumed in the literature, that familiarity affects the ease of understanding of noun-noun compounds. When compounds were familiar, they were judged to be sensible more quickly and were judged more often to be sensible than they were when they were unfamiliar. It was also found that when familiarity was properly controlled, the proposed preference for relational compounds over prop- erty ones largely disappeared. However, there was some evidence of relational preference in the proportions of sensibility judgments made to relational compounds; notably, when compounds were unfamiliar, relational ones were more often judged to be sensible than were property ones. It has been suggested that this effect may have been an artifact of the sensibility judgment task; that is, when speedy decisions were being made, the relational compounds appeared more sensible, because finding any vague interpretation would suffice. Therefore, in the present experiment, we wanted to replicate these relational preference effects in a comprehension task that required people to reflect more on the interpretation to the compound. ${ }^{5}$

As in Experiment 1, the compound type and familiarity variables were crossed in a $2 \times 2$ within-subjects design, using the same materials but a different comprehension task. We expected the familiarity effects to be replicated in this new task. The relational preference hypothesis would predict an effect of compound type, with the relational compounds being responded to more quickly than the property ones.

\section{Method}

Materials. The stimuli were identical to those in Experiment 1.

Procedure. The participants were instructed to judge the comprehensibility of compounds presented in a computerized, on-line task. The on-screen instructions asked them to think of an interpretation for the compound and, when they had found one, to respond with a keypress. They were then asked to enter the interpretation that they had found. They placed the index finger of their predominant hand on a function key of the keyboard (" " for the right-handed, "” for the left-handed). When they were ready, they pressed the function key once. The phrase they were being asked to judge was displayed immediately in the middle of the screen (beginning the measurement of the decision time). Once they had read and understood the word pair, they pressed the function key (ending the measurement of the decision time), typed in the interpretation that first came to mind, and pressed the function key again to continue with the next compound. If they found the compound to be incomprehensible (i.e., did not manage to find an interpretation for it), they typed in the word "no" and continued to the next compound.

The participants were asked to judge the compounds and to respond as accurately and quickly as possible. The instructions emphasized that their interpretations should be as clear and precise as possible. There was a practice session, akin to that used in Experiment 1 , involving five compounds that could be comprehended and five incomprehensible fillers. The materials were randomly ordered for each participant. The participants were tested individually, with each experimental session taking about $45 \mathrm{~min}$ to complete.

Participants. Twenty-five native English-speaking undergraduates from University College Dublin were paid to participate in the experiment. The group consisted of 11 women and 14 men from 20 to 33 years old.

Measures and scoring. Two measures were used: the decision time to think of an interpretation for the compound, and the proportion of times a compound was deemed comprehensible (i.e., an interpretation could be found for it).

Two independent judges, who were blind to the purpose of the study, analyzed the participants' interpretations of the compounds $(N=1,408)$, using several distinct categories, with the main ones being relation and property. This analysis revealed that 3 compounds classified in previous studies to be property compounds (book bicycle, spear tent, and organ bowl) were actually relational compounds; that is, most people responded to them with relational interpretations, 
rather than with property interpretations. ${ }^{6}$ Therefore, in our analysis, they were treated as relational, rather than as property, compounds. In the light of this finding, Experiment 1 was reanalyzed, but no changes were found in the pattern of results observed there.

The analysis of response times to compounds comprehended was conducted only on trials in which the participants produced either property or relational interpretations. The trials corresponded to a set of 272 relational familiar, 362 relational unfamiliar, 284 property familiar, and 297 property unfamiliar items, with the combination type for each of them defined according to the type of interpretation that each participant individually produced to it (see also Table 2). Prior to analysis, the data of 4 participants were excluded; 2 participants failed to understand the instructions and typed in semantically or associatively related concepts, rather than interpretations to the stimuli presented, and 2 participants were excluded because they judged a large amount of the critical comprehensible stimuli ( $\geq 30 \%)$ as noncomprehensible. The response times on 25 trials greater than $3 S D$ s from each of the remaining participants' grand mean were dropped from the response time analyses.

\section{Results and Discussion}

When people were asked to judge the comprehensibility of the compounds, it was again found that familiar compounds were more easily understood than unfamiliar compounds. However, there was little evidence for the relational preference hypothesis; relational compounds were not judged to be comprehensible more quickly or more often than were property compounds.

Response times to compounds comprehended. People comprehended the familiar compounds more quickly than the unfamiliar ones (i.e., they found an interpretation to them more quickly). A two-factor repeated measures ANOVA for the factors of compound type (relational or property) and familiarity (familiar or unfamiliar) was carried out by participants $\left(F_{1}\right)$ and by items $\left(F_{2}\right)$. The model specifications were identical to those in Experiment 1. This analysis revealed a main effect of familiarity, with the familiar compounds $(M=3,546.10, S D=2,763.94)$ being judged comprehensible more quickly than the unfamiliar compounds $(M=4,031.62, S D=2,931.87)\left[F_{1}(1,21)=\right.$ $14.94, M S_{\mathrm{e}}=4,829,605, p=.001 ; F_{2}(1,355)=7.59$, $\left.M S_{\mathrm{e}}=8,986,273, p=.006\right]$. The relational compounds $(M=3,733.45, S D=2,718.71)$ were responded to marginally more slowly than were the property compounds $(M=3,699.37, S D=2,857.22)$, although not reliably so $\left[F_{1}(1,21)=0.40, M S_{\mathrm{e}}=2,851,674, p=.53 ; F_{2}(1,355)=\right.$ $\left.0.69, M S_{\mathrm{e}}=8,986,273, p=.41\right]$. Neither was there a reliable interaction between familiarity and compound type

Table 2

Proportions (Counts and Row Percentages) of Relational, Property, and Other Interpretations for Familiar and

Unfamiliar Combinations in Experiment 2 When Mapped Against the Experimenters' Classifications (Condition)

\begin{tabular}{|c|c|c|c|c|c|c|}
\hline \multirow[b]{3}{*}{ Condition } & \multicolumn{6}{|c|}{ Interpretation } \\
\hline & \multicolumn{2}{|c|}{ Relational } & \multicolumn{2}{|c|}{ Property } & \multicolumn{2}{|c|}{ Other } \\
\hline & Count & $\%$ & Count & $\%$ & Count & $\%$ \\
\hline Relational familiar & 257 & 81.3 & 5 & 1.6 & 54 & 17.1 \\
\hline Relational unfamiliar & 351 & 77.6 & 28 & 6.2 & 73 & 16.2 \\
\hline Property familiar & 15 & 4.8 & 279 & 89.1 & 19 & 6.1 \\
\hline Property unfamiliar & 11 & 3.3 & 269 & 82.3 & 47 & 14.4 \\
\hline
\end{tabular}

$\left[F_{1}(1,21)=0.4, M S_{\mathrm{e}}=6,625,695, p=.71 ; F_{2}(1,355)=\right.$ $\left.2.99, M S_{\mathrm{e}}=8,986,273, p=.09\right]$. The means and standard deviations for the four conditions were as follows: relational familiar, $M=3,404.94, S D=2,575.63$; relational unfamiliar, $M=3,986.15, S D=2,801.32$; property familiar, $M=3,378.31, S D=2,677.70$; property unfamiliar, $M=4,004.15, S D=2,990.50$.

This result replicates the familiarity effect found in Experiment 1, using a new comprehension task, confirming our intuition that familiar compounds are more easily comprehended than unfamiliar ones. However, there is no support in these data for the relational preference hypothesis. ${ }^{7}$

To copper-fasten our conclusions, we reanalyzed the response time data defining familiarity in terms of occurrence or not occurrence in the BNC, using two-way ANOVAs, by participants and by items, with the same model specifications. These analyses revealed that compounds occurring in the corpus $(M=3,668.02, S D=$ $2,810.13$ ) were judged comprehensible more quickly than were those not occurring in the corpus $(M=3,950.53$, $S D=2,914.60)\left[F_{1}(1,21)=5.40, M S_{\mathrm{e}}=3,340,750, p=\right.$ $\left..03 ; F_{2}(1,353)=6.49, M S_{\mathrm{e}}=9,237,324, p=.01\right]$. There was no reliable main effect of compound type, and neither was there a reliable interaction between the two factors. The means and standard deviations for the four conditions were as follows: relational occurring in the BNC, $M=$ $3,526.79, S D=2,715.77$; relational not occurring in the BNC, $M=3,911.02, S D=2,712.72$; property occurring in the BNC, $M=3,612.37, S D=2,781.94$; property not occurring in the BNC, $M=3,806.93, S D=2,949.54$.

Proportions of compounds comprehended. In this experiment, people judged whether the presented compounds were comprehensible or incomprehensible. Thus, it was also possible to analyze people's responses in terms of the proportion of times people judged the presented compounds to be comprehensible, paralleling the proportion of sensibility judgments in Experiment 1. Using this measure, a two factor, repeated measures ANOVA was performed for the factors of compound type (relational or property) and familiarity (familiar or unfamiliar). This analysis revealed a main effect of familiarity, with the familiar compounds $(M=91.13, S D=10.11)$ being judged comprehensible more often than were the unfamiliar compounds $(M=72.72, S D=17.75)\left[F_{1}(1,20)=28.73\right.$, $M S_{\mathrm{e}}=248, p<.001 ; F_{2}(1,82)=26.98, M S_{\mathrm{e}}=250, p<$ .001]. Although marginally more relational compounds $(M=83.99, S D=16.45)$ were deemed to be comprehensible than property compounds $(M=79.86, S D=17.66)$, there was no reliable effect of compound type $\left[F_{1}(1,20)=\right.$ $2.70, M S_{\mathrm{e}}=132, p=.12 ; F_{2}(1,82)=1.35, M S_{\mathrm{e}}=250$, $p=.25]$. Neither was there a reliable interaction between compound type and familiarity $\left[F_{1}(1,20)=0.39, M S_{\mathrm{e}}=\right.$ $\left.66, p=.54 ; F_{2}(1,82)=0.10, M S_{\mathrm{e}}=250, p=.75\right]$. The means and standard deviations for the four conditions were as follows: relational familiar, $M=93.75, S D=7.65$; relational unfamiliar, $M=74.22, S D=17.19$; property familiar, $M=88.52, S D=11.69$; property unfamiliar, $M=71.21, S D=18.59$. 
The effects that were observed in the proportions of sensibility judgments in Experiment 1 disappeared when people were asked to find an interpretation for the compound in this experiment. Looking across the two experiments, this finding suggests that when people are making sensibility judgments, they are just developing a rough feel for whether or not an interpretation is likely to be found. Thus, relational compounds are more likely to be judged sensible-possibly, from their frequency in the language. However, this influence really occurs only under these specific conditions. When people are asked to think of a detailed meaning, there is no evidence of a parallel effect.

Interpretations produced. In this experiment, in addition to judging the comprehensibility of the compounds, the participants were asked to report the meaning that had occurred to them. These meanings were classified by independent judges into the different interpretation categories - that is, relational, property, hybrid, and so on. The two judges were given instructions defining the interpretation types, along with representative examples of each. The judges were asked to analyze each interpretation and to classify it as a relation, a property, or other. Any disagreements were resolved by discussion between the judges. Of the total number of interpretations produced $(N=1,408), 79.2 \%(n=608 / 768)$ of the relational compounds yielded relational interpretations and $85.7 \%(n=$ $548 / 640)$ of the property compounds yielded property interpretations. In her second experiment, Gagné (2000) reported that the majority (52\%) of responses for property compounds did not involve conceptual combination. It is clear that this conclusion is not upheld by our analysis. Table 2 presents in more detail the proportions of relation, property, and other interpretations for familiar and unfamiliar compounds in Experiment 2.

\section{GENERAL DISCUSSION}

To summarize, the present experiments place future conceptual combination research on a firmer footing with the proper control of familiarity. They also show that familiarity has a significant effect on people's ease of understanding of compounds. Finally, they suggest that there appears to be no a priori preference for one compound type over another. The implications of these results can, perhaps, be best spun out by answering the questions posed at the beginning of the article.

Has familiarity been adequately controlled in previous studies? The short answer is "no." The ratings study shows that several previous studies had familiar and unfamiliar compounds unevenly distributed across key treatment conditions. Since it is now known from Experiments 1 and 2 that familiarity has a marked effect on ease of comprehension, one must consider the results of many of these previous studies to be, at best, unsafe or, at worst, wrong.

Do the key results for relational preference still hold when suitably controlled stimuli are used? Again, the short answer to this question is "no." When the key study on this relational preference issue is replicated and famil- iarity is appropriately controlled, the relational preference effect is not reliable anymore. Recall that Gagné (2000) found that relational compounds were judged to be sensible reliably more quickly than property compounds. In our familiarity-controlled Experiment 1, this effect was not replicated. Although there is some evidence for relational preference in the proportions of sensibility judgments (Experiment 1), this effect seems to be specific to this particular task. In Experiment 2, where the tests were extended to a comprehension task, relational preference effects were also not replicated. Finally, and contrary to previous reports, it was found that the majority of property combinations were predominantly comprehended as such and involved conceptual combination.

Is there converging evidence for the relational preference hypothesis in people's comprehension of compounds? The short answer to this question is "not really." When one looks across the different tasks that have been used and the failure to replicate relational preference effects under more controlled conditions, it is hard to defend the relational preference issue. It now appears that there is no particular primacy in relational compounds. There may well be specific sets of relational compounds that can be shown to be more easily comprehended than are property ones, but we suspect that there would be little generality to such phenomena. There will be other sets of property compounds that can be shown to be more easily comprehended. Such results will show only that some compounds access specific knowledge more directly and easily in the process of understanding because of the prior activation, salience, or some other aspect of knowledge. There is no sense in which relational interpretations as a general class are easier than property interpretations. They are all interpretations cut from the cloth of knowledge by processes that operate with equal fluency.

There is a final question that one can add to these three, having now cleared up some of the empirical baggage from the scene - namely, where do these empirical effects leave the different models of conceptual combination? Theoretically, the present results favor the constraint and dual-process accounts of conceptual combination. It may be remembered that these models do not give any special status to relational or property interpretations. Although they propose different explanatory mechanisms for the production of the two interpretation types, both models will produce either interpretation type, largely as a result of the knowledge entering the combination process. Does this mean the CARIN model is completely wrong? We believe not.

The CARIN model always had the problem that it did not offer a good account for property interpretations. However, if it is restricted to an account of relational interpretations, it clearly has much to offer. In essence, as a model, it argues that the (relational) meanings associated with the words used in known compounds have an impact on the comprehension of novel compounds. Thus, the serious question for the constraint and dual-process models is, how do they reflect the influence of this type of distributional knowledge and, indeed, of familiarity? 


\section{REFERENCES}

Blasko, D. G., \& Connine, C. M. (1993). Effects of familiarity and aptness on metaphor processing. Journal of Experimental Psychology: Learning, Memory, \& Cognition, 19, 295-308.

Bock, J. S., \& ClifTON, C., JR. (2000). The role of salience in conceptual combination. Memory \& Cognition, 28, 1378-1386.

Burnard, L. (1995). Users' reference guide for the British National Corpus. Oxford: Oxford University Computing Service.

Cohen, B., \& Murphy, G. L. (1984). Models of concepts. Cognitive Science, 8, 27-58.

Connine, C. M., Mullennix, J., Shernoff, E., \& Yelen, J. (1990). Word familiarity and frequency in visual and auditory word recognition. Journal of Experimental Psychology: Learning, Memory, \& Cognition, 16, 1084-1096.

Costello, F. J., \& Keane, M. T. (1997). Polysemy in conceptual combination: Testing the constraint theory of combination. In M. G. Shafto \& P. Langley (Eds.), Proceedings of the Nineteenth Annual Conference of the Cognitive Science Society (pp. 137-142). Mahwah, NJ: Erlbaum.

Costello, F. J., \& KeAne, M. T. (2000). Efficient creativity: Constraintguided conceptual combination. Cognitive Science, 24, 299-349.

Costello, F. J., \& Keane, M. T. (2001). Testing two theories of conceptual combination: Alignment versus diagnosticity in the comprehension and production of combined concepts. Journal of Experimental Psychology: Learning, Memory, \& Cognition, 27, 255-271.

Downing, P. (1977). On the creation and use of English compound nouns. Language, 53, 810-842.

Estes, Z., \& GLUCKSBERG, S. (2000). Interactive property attribution in concept combination. Memory \& Cognition, 28, 28-34.

GaGNÉ, C. L. (2000). Relation-based combinations versus property-based combinations: A test of the CARIN theory and dual-process theory of conceptual combination. Journal of Memory \& Language, 42, 365-389.

GaGNÉ, C. L. (2001). Relation and lexical priming during the interpretation of noun-noun combinations. Journal of Experimental Psychology: Learning, Memory, \& Cognition, 27, 236-254.

GaGNÉ, C. L. (2002). Metaphoric interpretations of comparison-based combinations. Metaphor \& Symbol, 17, 161-178.

GaGné, C. L., \& SHOBEN, E. J. (1997). Influence of thematic relations on the comprehension of modifier-noun combinations. Journal of Experimental Psychology: Learning, Memory, \& Cognition, 23, 71-87.

GentNER, D. (1983). Structure-mapping: A theoretical framework for analogy. Cognitive Science, 7, 155-170.

GernsBACHER, M. A. (1984). Resolving 20 years of inconsistent interactions between lexical familiarity and orthography, concreteness, and polysemy. Journal of Experimental Psychology: General, 113, 256-281.

Glucksberg, S., McGlone, M. S., \& Manfredi, D. (1997). Property attribution in metaphor comprehension. Journal of Memory \& Language, 36, 50-67.

Goldvarg, Y., \& Glucksberg, S. (1998). Conceptual combinations: The role of similarity. Metaphor \& Symbol, 13, 243-255.

Gray, K. C., \& SMITH, E. E. (1995). The role of instance retrieval in understanding complex concepts. Memory \& Cognition, 23, 665-674.

Hampton, J. A. (1987). Inheritance of attributes in natural concept conjunctions. Memory \& Cognition, 15, 55-71.

Hoey, M. (2005). Lexical priming: A new theory of words and language. London: Routledge.

JESPERSEN, O. (1942). A modern English grammar on historical principles: Vol. 7. Morphology. London: Allen \& Unwin.

Keane, M. T., \& Costello, F. J. (2001). Setting limits on analogy: Why conceptual combination is not structural alignment. In D. Gentner, K. J. Holyoak, \& B. N. Kokinov (Eds.), The analogical mind: Perspectives from cognitive science (pp. 287-312). Cambridge, MA: MIT Press.

Keane, M. T., Ledgeway, T., \& Duff, S. (1994). Constraints on analogical mapping: A comparison of three models. Cognitive Science, 18, 387-438.

Kilgarriff, A., \& Grefenstette, G. (2003). Introduction to the special issue on the Web as corpus. Computational Linguistics, 29, 333-347.

LEVI, J. N. (1978). The syntax and semantics of complex nominals. New York: Academic Press.

Lynott, D., Tagalakis, G., \& Keane, M. T. (2004). Conceptual combination with PUNC. Artificial Intelligence Review, 22, 247-267.
Markman, A. B., \& Wisniewski, E. J. (1997). Similar and different: The differentiation of basic level categories. Journal of Experimental Psychology: Learning, Memory, \& Cognition, 23, 54-70.

Medin, D. L., \& Shoben, E. J. (1988). Context and structure in conceptual combination. Cognitive Psychology, 20, 158-190.

Murphy, G. L. (1988). Comprehending complex concepts. Cognitive Science, 12, 529-562.

MurPhy, G. L. (2002). The big book of concepts. Cambridge, MA: MIT Press.

SHOBEN, E. J. (1993). Nonpredicating conceptual combinations. In G. V. Nakamura, R. M. Taraban, \& D. L. Medin (Eds.), The psychology of learning and motivation (Vol. 29, pp. 391-409). New York: Academic Press.

Shoben, E. J., \& Gagné, C. L. (1997). Thematic relations and the creation of combined concepts. In T. B. Ward, S. M. Smith, \& J. Vaid (Eds.), Creative thought: An investigation of conceptual structures and processes (pp. 31-50). Washington, DC: American Psychological Association.

Springer, K., \& Murphy, G. L. (1992). Feature availability in conceptual combination. Psychological Science, 3, 111-117.

Tagalakis, G., \& Keane, M. T. (2004). Automating the interpretation of novel noun-noun compounds using WordNet. In P. Gervás \& K. M. Gupta (Eds.), Proceedings of the European Conference on Case-Based Reasoning 2004 Workshops (pp. 225-236). Madrid: Complutense University of Madrid.

WiSNIEWSKI, E. J. (1996). Construal and similarity in conceptual combination. Journal of Memory \& Language, 35, 434-453.

Wisniewski, E. J., \& GentNeR, D. (1991). On the combinatorial semantics of noun pairs: Minor and major adjustments to meaning. In G. Simpson (Ed.), Understanding word and sentence (pp. 241-284). Amsterdam: North-Holland.

WisNiEWsKi, E. J., \& Love, B. C. (1998). Relations versus properties in conceptual combination. Journal of Memory \& Language, 38, 177202.

\section{NOTES}

1. The concepts judged as familiar that do not occur in the BNC are family town, finger nerve, flu pills, fork tongue, gas crisis, job conflict, maternal pains, snail post, student equipment, traumatic tale, vapor drops, and winter breeze.

2. These are hits for compounds that can be interpreted as meaningful concept combinations without any punctuation separating the constituent concepts. A tokenizer and filtering program that exploits the standard Google API was used to retrieve the sentence context for these compounds, which were then inspected by the authors.

3. Although we would have liked to have equal numbers of targets and fillers, pilots revealed that this made the experiment too long. The smaller numbers of fillers raises the possibility that the participants might be more likely to respond that a compound is sensible, rather than nonsensible. However, even if such a bias existed, it should uniformly impact the experiment's critical manipulations.

4. Tukey $95.0 \%$ simultaneous confidence intervals for pairwise comparisons among levels of the compound type factor $(\mathrm{CI}=-88.45$, 76.54) contain the true value of the population parameter.

5. Gagné (2000, Experiment 2) attempted to assess people's actual understanding of the compounds by first giving them a sensibility judgment task and then, later, asking them to write interpretations for the same compounds. Although the participants were given instructions for both parts at the beginning of the experiment, these tasks were blocked; people judged the sensibility of all the compounds and then, later, interpreted all the compounds. In the present experiment, we interleaved the response time task and the interpretation task; people judged a compound to be comprehensible/incomprehensible and then immediately interpreted it, before moving on to the next compound.

6. The phrases in question appeared originally in Wisniewski (1996). Estes and Glucksberg (2000) have also reported that 14 of Wisniewski's 20 high-salience, high-relevance, property-based stimuli were actually interpreted relationally by some participants.

7. Tukey $95.0 \%$ simultaneous confidence intervals for pairwise comparisons among levels of the compound type factor $(\mathrm{CI}=-321.10$, 191.90) contain the true value of the population parameter. 
APPENDIX A

Experimental Items for Gagné's (2000) Experiments 1 and 2

\begin{tabular}{|c|c|c|c|}
\hline \multicolumn{2}{|c|}{ Relational } & \multicolumn{2}{|c|}{ Property } \\
\hline chocolate plant & mountain magazine & apartment hotel & mosquito oyster \\
\hline chocolate utensils & musical town & apple duck & motorcycle screwdriver \\
\hline college headache & office antiques & apple pear & mouse onion \\
\hline college magazine & office plant & bed tea & mouse squirrel \\
\hline cooking remedy & paper antiques & book bicycle & organ bowl \\
\hline cooking treatment & paper equipment & bus truck & organ piano \\
\hline family town & plastic crisis & coat shirt & pistol rifle \\
\hline family utensils & plastic toy & coffee sword & robin canary \\
\hline financial headache & servant language & drill pamphlet & robin termite \\
\hline financial remedy & servant scandal & fork scarf & saxophone couch \\
\hline floral toy & student equipment & fork spoon & shark coconut \\
\hline gas cloud & urban light & goose horse & shark piranha \\
\hline gas crisis & water bird & knife chisel & spear tent \\
\hline home language & water money & lettuce cabbage & stool chair \\
\hline home light & wood money & magazine newspaper & tie trumpet \\
\hline mountain bird & wood treatment & mosquito fly & whiskey beer \\
\hline
\end{tabular}

APPENDIX B

Rating Study: Familiar Compounds

\begin{tabular}{|c|c|c|c|}
\hline \multicolumn{2}{|c|}{ Relational } & \multicolumn{2}{|c|}{ Property } \\
\hline $\begin{array}{l}\text { adventure comedy } \\
\text { air power } \\
\text { college magazine } \\
\text { cream sauce } \\
\text { family town } \\
\text { financial headache } \\
\text { financial remedy } \\
\text { finger nerve } \\
\text { flu pills } \\
\text { gas cloud } \\
\text { gas crisis } \\
\text { gas lamp } \\
\text { job conflict } \\
\text { maternal pains } \\
\text { morning prayers } \\
\text { mountain bird } \\
\text { municipal court } \\
\text { murder report }\end{array}$ & $\begin{array}{l}\text { office plant } \\
\text { oil treatment } \\
\text { party dance } \\
\text { picture story } \\
\text { plastic toy } \\
\text { sex hormone } \\
\text { smoke problem } \\
\text { song book } \\
\text { student equipment } \\
\text { student network } \\
\text { traumatic tale } \\
\text { urban riots } \\
\text { vapor drops } \\
\text { water bird } \\
\text { winter breeze } \\
\text { wood shavings } \\
\text { wood treatment }\end{array}$ & $\begin{array}{l}\text { barrel chest } \\
\text { bell jar } \\
\text { bird brain } \\
\text { bow leg } \\
\text { bubble car } \\
\text { bullet train } \\
\text { club foot } \\
\text { computer mind } \\
\text { crow feet } \\
\text { devil woman } \\
\text { dragon fly } \\
\text { fork tongue } \\
\text { hawk eye }\end{array}$ & $\begin{array}{l}\text { hump back } \\
\text { ice maiden } \\
\text { iron man } \\
\text { lion heart } \\
\text { maiden speech } \\
\text { maiden voyage } \\
\text { mushroom cloud } \\
\text { pot belly } \\
\text { rat race } \\
\text { saddle bag } \\
\text { silver tongue } \\
\text { snail post } \\
\text { stick insect }\end{array}$ \\
\hline
\end{tabular}




\section{APPENDIX C}

Rating Study: Proportions of Familiar (F) and Unfamiliar (UF) Judgments and Mean Ratings for Property Compounds

\begin{tabular}{|c|c|c|c|c|c|c|c|}
\hline Stimuli & $\mathrm{F}(\%)$ & UF (\%) & Mean & Stimuli & $\mathrm{F}(\%)$ & UF $(\%)$ & Mean \\
\hline accordion pleat & 20.5 & 79.5 & 2.48 & meadow carpet & 0 & 97.4 & 1.58 \\
\hline angel pig & 7.7 & 92.3 & 1.35 & mirror lake & 10.3 & 71.8 & 2.32 \\
\hline apartment hotel ${ }^{*}$ & 30.8 & 61.5 & 3.26 & mirror liquid & 0 & 100.0 & 1.68 \\
\hline apple duck ${ }^{*}$ & 0 & 100.0 & 1.52 & mosquito fly* & 46.2 & 46.2 & 4.03 \\
\hline apple pear* & 5.1 & 89.7 & 1.84 & mosquito oyster* & 0 & 97.4 & 1.16 \\
\hline barrel chest & 56.4 & 41.0 & 3.97 & motorcycle screwdriver* & 0 & 94.9 & 1.61 \\
\hline bed tea* & 10.3 & 84.6 & 1.94 & mouse onion* & 0 & 100.0 & 1.13 \\
\hline bell jar & 69.2 & 23.1 & 4.81 & mouse squirrel $^{*}$ & 2.6 & 97.4 & 1.45 \\
\hline bird brain & 89.7 & 7.7 & 5.74 & mushroom cloud & 74.4 & 15.4 & 5.74 \\
\hline blimp chicken & 2.6 & 97.4 & 1.42 & nanny camera & 20.5 & 76.9 & 2.13 \\
\hline bomb article & 0 & 94.9 & 1.55 & octopus table & 0 & 97.4 & 1.35 \\
\hline book bicycle* & 2.6 & 97.4 & 1.39 & organ bowl* & 5.1 & 89.7 & 1.58 \\
\hline bow leg & 59.0 & 28.2 & 4.84 & organ piano* & 15.4 & 79.5 & 2.29 \\
\hline brocade poem & 2.6 & 94.9 & 1.45 & pig face & 48.7 & 41.0 & 3.94 \\
\hline bubble car & 56.4 & 35.9 & 4.00 & pigeon toe & 33.3 & 61.5 & 3.29 \\
\hline bullet train & 66.7 & 25.6 & 5.06 & pistol rifle* & 15.4 & 79.5 & 2.10 \\
\hline bus truck ${ }^{*}$ & 0 & 100.0 & 1.52 & plier stapler & 0 & 97.4 & 1.55 \\
\hline cherry paint & 23.1 & 71.8 & 2.74 & porcupine carpet & 0 & 100.0 & 1.55 \\
\hline claw toe & 17.9 & 71.8 & 2.10 & pot belly & 94.9 & 0 & 6.55 \\
\hline club foot & 56.4 & 28.2 & 4.81 & rake comb & 7.7 & 87.2 & 1.94 \\
\hline coat shirt* & 5.1 & 92.3 & 1.68 & rat race & 89.7 & 5.1 & 6.19 \\
\hline coffee sword* & 0 & 94.9 & 1.45 & razor insult & 10.3 & 82.1 & 1.94 \\
\hline computer mind & 59.0 & 35.9 & 4.16 & robin canary* & 2.6 & 97.4 & 1.55 \\
\hline copper sky & 20.5 & 71.8 & 2.52 & robin termite* & 0 & 100.0 & 1.61 \\
\hline crow feet & 71.8 & 23.1 & 4.97 & rock bagel & 0 & 100.0 & 1.42 \\
\hline devil woman & 74.4 & 20.5 & 5.06 & rubber steak & 5.1 & 79.5 & 2.19 \\
\hline dragon fly & 100.0 & 0 & 6.55 & saddle bag & 64.1 & 28.2 & 5.39 \\
\hline dragon woman & 30.8 & 66.7 & 3.23 & sandpaper skin & 12.8 & 56.4 & 3.03 \\
\hline drill pamphlet* & 2.6 & 92.3 & 1.58 & saxophone couch* & 0 & 100.0 & 1.13 \\
\hline egg ball & 2.6 & 97.4 & 1.42 & shark coconut & 2.6 & 97.4 & 1.52 \\
\hline elephant sail & 5.1 & 92.3 & 1.48 & shark lawyer & 23.1 & 66.7 & 2.79 \\
\hline fire drink & 0 & 92.3 & 1.68 & shark piranha* & 5.1 & 89.7 & 1.58 \\
\hline fork scarf & 0 & 100.0 & 1.10 & shark politician & 12.8 & 71.8 & 1.97 \\
\hline fork spoon* & 5.1 & 89.7 & 1.52 & silver tongue & 69.2 & 17.9 & 5.10 \\
\hline fork tongue* & 53.8 & 41.0 & 4.65 & skunk cabbage & 5.1 & 92.3 & 1.45 \\
\hline fossil executive & 0 & 97.4 & 1.42 & skyscraper tree & 2.6 & 89.7 & 1.74 \\
\hline goose horse* & 0 & 100.0 & 1.16 & snail post & 51.3 & 43.6 & 3.32 \\
\hline handcuff contract & 0 & 97.4 & 1.61 & spear tent* & 0 & 100.0 & 1.58 \\
\hline hawk eye & 76.9 & 15.4 & 5.74 & spider engine & 17.9 & 82.1 & 1.87 \\
\hline hump back & 82.1 & 7.7 & 6.06 & sponge memory & 20.5 & 66.7 & 2.65 \\
\hline ice feet & 10.3 & 74.4 & 2.42 & stick insect & 74.4 & 10.3 & 5.94 \\
\hline ice maiden & 69.2 & 20.5 & 5.71 & stool chair* & 2.6 & 89.7 & 1.84 \\
\hline iron man & 94.9 & 2.6 & 6.48 & surgeon butcher & 10.3 & 89.7 & 1.74 \\
\hline jackal genius & 0 & 100.0 & 1.23 & thunder lecture & 0 & 94.9 & 1.52 \\
\hline jail job & 12.8 & 84.6 & 2.32 & thunder march & 5.1 & 92.3 & 1.74 \\
\hline kangaroo jacket & 10.3 & 87.2 & 2.06 & thunder voice & 15.4 & 61.5 & 2.77 \\
\hline knife chisel $^{*}$ & 2.6 & 92.3 & 1.65 & tie trumpet* & 0 & 100.0 & 1.29 \\
\hline lemon paint & 17.9 & 74.4 & 2.39 & tower cart & 0 & 94.9 & 1.48 \\
\hline lettuce cabbage* & 2.6 & 94.9 & 1.48 & turtle walker & 2.6 & 94.9 & 1.65 \\
\hline lion heart & 71.8 & 15.4 & 5.32 & whiskey beer* & 10.3 & 87.2 & 2.03 \\
\hline mackerel sky & 10.3 & 87.2 & 1.71 & zebra bag & 15.4 & 79.5 & 2.19 \\
\hline magazine newspaper* & 7.7 & 87.2 & 1.87 & zebra finch & 7.7 & 92.3 & 1.52 \\
\hline maiden speech & 56.4 & 33.3 & 4.58 & zebra fish & 35.9 & 64.1 & 2.29 \\
\hline maiden voyage & 92.3 & 0 & 6.42 & & & & \\
\hline
\end{tabular}

*Experimental items Gagné (2000) selected from Wisniewski (1996). All of them have been judged as unfamiliar. 
APPENDIX D

Critical Stimuli, Mean Familiarity Ratings, and Fillers for Experiments 1 and 2

\begin{tabular}{|c|c|c|c|c|}
\hline Relational & $M_{\mathrm{F}}$ & Property & $M_{\mathrm{F}}$ & Fillers \\
\hline adventure comedy & 3.94 & apple pear & 1.84 & butterfly molar \\
\hline air power & 4.26 & barrel chest & 3.97 & church pelvis \\
\hline birth rash & 3.42 & bell jar & 4.81 & corridor mustard \\
\hline chocolate utensils & 1.71 & book bicycle & 1.39 & cotton spark \\
\hline chocolate wreath & 1.65 & bow leg & 4.84 & deposit nostril \\
\hline city committee & 3.29 & bubble car & 4.00 & fault futurity \\
\hline college headache & 3.03 & bullet train & 5.06 & feather introspection \\
\hline college magazine & 6.26 & bus truck & 1.52 & feeler trafficker \\
\hline cooking hole & 2.10 & coffee sword & 1.45 & flower megaphone \\
\hline cooking remedy & 2.97 & computer mind & 4.16 & formula fringe \\
\hline family cow & 2.90 & crow feet & 4.97 & fruit dignity \\
\hline family town & 3.71 & devil woman & 5.06 & garden defeatism \\
\hline financial remedy & 4.26 & dragon fly & 6.55 & glove iris \\
\hline finger nerve & 3.39 & fork scarf & 1.10 & inference oak \\
\hline fish gland & 2.48 & handcuff contract & 1.61 & jug riot \\
\hline gas cloud & 4.55 & hawk eye & 5.74 & knot budget \\
\hline gas lamp & 6.03 & hump back & 6.06 & lettuce fog \\
\hline hand language & 3.23 & lion heart & 5.32 & locker gravy \\
\hline headache season & 2.84 & magazine newspaper & 1.87 & lung weaver \\
\hline heat iron & 2.42 & maiden speech & 4.58 & marble vowel \\
\hline horse toy & 2.03 & meadow carpet & 1.58 & mascot nostalgia \\
\hline milk virus & 1.39 & mirror lake & 2.32 & memory oboe \\
\hline morning prayers & 6.19 & mouse onion & 1.13 & mill amnesty \\
\hline mountain cloud & 2.87 & mushroom cloud & 5.74 & mirror flour \\
\hline office antiques & 3.03 & octopus table & 1.35 & mummy hatching \\
\hline office plant & 5.00 & organ bowl & 1.58 & overcoat flu \\
\hline paper album & 2.58 & pigeon toe & 3.29 & prism tobacco \\
\hline picture story & 4.55 & rat race & 6.19 & piano loaf \\
\hline pine dust & 2.13 & rubber steak & 2.19 & quilt cracker \\
\hline plastic crisis & 2.29 & shark politician & 1.97 & rabbit electors \\
\hline rain lake & 1.90 & skunk cabbage & 1.45 & soybean attitude \\
\hline servant scandal & 2.48 & snail post & 3.32 & spy vinyl \\
\hline sex hormone & 5.61 & spear tent & 1.58 & stork dome \\
\hline song book & 6.23 & sponge memory & 2.65 & subway mustachio \\
\hline sports tension & 2.65 & stick insect & 5.94 & touchdown ideogram \\
\hline steam equipment & 3.19 & stool chair & 1.84 & tourist hoof \\
\hline urban riots & 4.71 & surgeon butcher & 1.74 & valve oak \\
\hline vegetable cube & 3.16 & thunder march & 1.74 & villa electron \\
\hline voice vote & 1.77 & thunder voice & 2.77 & vinaigrette escalator \\
\hline water bird & 4.42 & turtle walker & 1.65 & week taw \\
\hline water money & 2.00 & whiskey beer & 2.03 & whale roulette \\
\hline winter breeze & 5.13 & zebra fish & 2.29 & window dogma \\
\hline
\end{tabular}

(Manuscript received January 30, 2004; revision accepted for publication June 28, 2005.) 